\title{
Mortality Trends and Disparities Among Racial/Ethnic and Sex Subgroups in New York City, 1990 to 2000
}

\author{
Katherine Freeman • Joel Zonszein • \\ Nadia Islam • Arthur E. Blank • Alvin H. Strelnick
}

Published online: 22 April 2010

(C) The Author(s) 2010. This article is published with open access at Springerlink.com

\begin{abstract}
New York City census data for 1990 and 2000 for all-cause and disease-specific mortality adjusted by age were examined by race/ethnicity. Primary cause of death was coded as HIV/AIDS, cardiovascular disease, coronary heart disease, acute myocardial infarction, stroke, diabetes, or cancer. For White, Black, Hispanic and Asian groups, relative mortality ratios (RMR) were derived for 2000 relative to 1990. Ratios of RMR's for minority groups were derived relative to Whites. From 1990 to 2000, HIV, cancer, CVD, CHD, AMI, and stroke-related mortality decreased. Decreases in HIV-related mortality were notably less for minority males. Diabetes mortality rates rose dramatically, with Hispanic and Asian males having notably greater increases than White males. Increases in mortality among Asians exceeded those of other groups, and appear to correspond with increased immigration/ acculturation. Mortality shifts among different diseases and racial groups should alert public health officials to consider immigration patterns in designing, implementing, and
\end{abstract}

K. Freeman $(\bowtie)$

Department of Epidemiology and Population Health, Albert Einstein College of Medicine/Montefiore Medical Center, 111 East 210th Street, Bronx, NY 10467, USA

e-mail:kfreeman@montefiore.org

J. Zonszein

Department of Medicine, Albert Einstein College of Medicine, Bronx, NY, USA

\section{N. Islam}

Center for the Study of Asian American Health, New York University School of Medicine, New York City, NY, USA

A. E. Blank · A. H. Strelnick

Department of Family Medicine, Albert Einstein College

of Medicine, Bronx, NY, USA evaluating interventions to prevent disease-related mortality, with a goal to eliminate disparities

Keywords Mortality - Mortality ratio - Disparities · Immigration

\section{Introduction}

While New York City's overall death rates have fallen during the last decade in parallel with the rest of the country, improvements have not been distributed equally among racial and ethnic groups. During the 1980s, the difference in mortality rates between Blacks and Whites actually widened [1, 2], health indicators including mortality for Hispanics worsened, and the gap between Whites and Hispanics grew [3, 4]. In addition, studies have found that Asian Americans fare much worse than White Americans with regard to specific indicators such as death from liver cancer [5]. Several factors, including healthcare and policy improvements, changing health behavior patterns, and demographic shifts have affected overall mortality rates in NYC and across the nation dramatically. For example, NYC experienced a significant reduction in violent crimes, and the introduction of Highly Active AntiRetroviral Therapies (HAART) for more effective treatment of HIV and AIDS, resulted in great improvements in mortality. In contrast, the increasing incidence of obesity in the US by about $50 \%$ during this period, has been associated with a one-third increase in the rate of type 2 diabetes and its chronic and lethal cardiovascular complications [6]. Type 2 diabetes has afflicted all major racial and socioeconomic groups [7], with higher rates in NYC among racial minorities [8]. Relative to rates of increase in diabetes among Caucasians (29.3\%) and African Americans 
(26.1\%), rates among Hispanics and Others were much greater, 37.7 and $87.6 \%$, respectively [8].

Inequalities in health are closely linked to socioeconomic status, immigration and acculturation, and race or ethnicity. During the 1990's, dramatic changes in the racial/ethnic mix of NYC's population occurred, with a decrease in the White population $(-11.4 \%)$, and increases in Black (6.2\%), Hispanic (23.8\%), and Asian populations (62.7\%) [9]. These changes were due in part to the Immigration Reform and Control Act (IRCA) of 1986, which provided amnesty to certain undocumented immigrants who entered the United States before January 1, 1982, and made it easier for family members of low-skilled laborers to enter the country. In response to events surrounding Tiananmen Square protests of 1989, an executive order was issued to facilitate the process by which Chinese foreign students obtained permanent residency in the United States. The Immigration Act of 1990 increased the total number of immigrants by $40 \%$ nationwide, and employment based visas threefold. Those with college and graduate level education-specifically in science and engineering, were then allowed to obtain temporary work visas, which facilitated change in visa status to permanent. Other programs (Diversity Visa Program, Immigrant Visa Lottery) were established during the 1990's facilitating large increases in South Asians to migrate to the US and NYC in particular [10]. These Acts contributed to the $9.4 \%$ increase in NYC's population from 1990 to 2000 after decades of decline.

In 2000, an estimated $44 \%$ of adults in NYC were foreign born. Of the 836,000 who emigrated to NYC from outside the US between 1990 and 2000, 20.9\% were Dominican, $16.7 \%$ were Afro-Caribbean, $14.0 \%$ were Chinese, and $13.7 \%$ were Mexican [11]. Immigrants face many challenges including substandard and costly housing and residential segregation in low-income neighborhoods. Prior to The Immigration Act 1990 and Diversity Visa Program, newly arriving immigrants generally came with lower levels of education than US born residents, and were also at a wage disadvantage which may persist for decades. Although immigrants may be entitled to public health programs, access to healthcare is often complicated by visa status. Such issues may be compounded by language barriers needed to advocate their rights in court. Reports on the health of immigrants in NYC [12] cited cultural and language barriers, undocumented immigration status, toxic environmental exposure, and poor health behaviors related to diet and smoking as important health deterrents, and mortality inequalities by neighborhood income [13]. From 1990 to 2000, differences between high and low income community neighborhoods in New York City were associated with differing trends in mortality, with the most notable being a greater reduction in deaths due to AIDS in the wealthiest neighborhoods compared with the poorest [13]. Thus our hypothesis is that immigration and socioeconomic status and their often collinear relationship using race/ethnicity as a proxy, likely contribute to differing trends in mortality.

\section{Methods}

\section{Theoretical Model}

Using an ecological approach, we propose the EvansStoddart model of determinants of health to identify possible factors that may contribute to differences in trends in mortality among race/ethnicity groups [14]. We contextualize our analysis using two aspects of this model, the social environment component-one of the three significant determinants of health that include physical environment and genetic endowment, and the individual response component-an intermediate component influenced by the prior three determinants. Our hypothesis is based on the expectation that changes in mortality rates among select racial/ethnic groups will parallel changes in immigration patterns and changes in obesity rates, reflected in the social environment and the individual response components, respectively. With regard to immigration, we expect that, in the aggregate, decreased health and hence increased mortality will be associated with increased immigration. Our expectations are based on the following. Immigrants in general experience more stresses from leaving family behind and from constraints on employment due to language barriers. Typically they have emigrated with lower levels of education than non-immigrant residents, and experience significant barriers in accessing health services. These factors, part of the social environment component of the Evans-Stoddart model, encompass "social networks" and work related factors.

With regard to obesity, we expect that increases in the obesity rate will correspond with increases in mortality. The Evans-Stoddart model presents the relationship between individual response to behavior and biology. Obesity, a key example of a behavioral risk factor for allcause mortality as well as death from acute myocardial infarction [15], may be influenced by genetic predisposition, dietary or physical activity patterns, and cultural traditions, and has been cited as a major driver of chronic disease disparities [16]. Rates of overweight and obesity have been increasing more rapidly in African Americans and Latinos relative to Caucasians [17]. Asian-Americans in general have a lower prevalence of being overweight or obese, although their threshold of BMI for adverse cardiovascular effects is lower [18]. In addition, some studies have documented that particular Asian American 
subgroups, including Filipinos and Asian Indians, have higher rates of obesity than their White counterparts [19].

The Healthy People 2010 initiative has made the elimination of disparities in health its primary goal [20]. Available aggregate mortality data for NYC from 1990 through 2000 stratified by race/ethnicity have provided an opportunity to examine mortality trends in this large and racially diverse population. The objective of this paper is to examine changes between 1990 and 2000 for all-cause and disease-specific mortality in NYC by race/ethnicity, with attention to trends and differences in trends among select racial/ethnic groups within the context of changing background demographics.

\section{Datasets and Populations}

New York City mortality records for the two 5-year periods of 1988-1992 and 1998-2002 were compiled from computer tapes provided by the New York City Department of Health (NYCDOH), Office of Vital Records. Data were deidentified to preserve confidentiality. Race/ethnicity was obtained as White, Black, Hispanic and Asian. A physician coded underlying causes of death according to ICD-9 [21] (1988-1992) and ICD-10 [22] (1998-2002) and merged NYCDOH mortality records with US Census Public Use Microdata Samples (PUMS) to calculate crude and ageadjusted mortality rates. Categories analyzed were deaths from all causes, and cause-specific mortality abstracted from the death certificate as underlying causes of death: HIV/AIDS, cardiovascular disease, coronary heart disease, acute myocardial infarction, stroke, diabetes, and cancer, with ICD-9 and ICD-10 codes listed in Table 1. Data were provided to us as summary statistics only.

\section{Statistical Methods}

The population was limited to persons 35 years and older because the cutpoint of 35 was consistent with categories

Table 1 ICD-9 and ICD-10 codes for specific cause of death

\begin{tabular}{llc}
\hline Diagnosis & ICD-9 & ICD-10 \\
\hline HIV [23] & 042 & B20-B24 \\
Cancer & $140-208$ & C00-C96 \\
CVD & $390-495$ & $100-199$ \\
CHD & $410-414,492.2$ & $120-125$ \\
AMI & 410 & $121-122$ \\
Stroke & $430-438$ & I60-I69 \\
Diabetes & 250 & E10-E14 \\
\hline
\end{tabular}

$H I V$, human immunodeficiency virus; $A M I$, acute myocardial infarction; $C H D$, coronary heart disease; $C V D$, cardiovascular disease listed by the National Vital Statistics Report; this report cites that rates of change in mortality begin to double for every decade following age 35 relative to categories between ages 1 and 35 years [24]. Age -adjusted rates for all-cause and cause-specific mortality for men and women in different race or ethnic subgroups were estimated using mortality records from 1988-1992 and 1998-2002, with US census data for 1990 and 2000, respectively, as referent groups. Within each race/ethnic and sex subgroup, the relative mortality ratio (RMR) for 1990 and 2000 using the age-adjusted mortality rate for year 2000 as the numerator and that for 1990 as the denominator, was estimated to evaluate the trend in mortality from 1990 to 2000 . The $95 \%$ confidence intervals were derived for all mortality ratios, under the assumption that these data are derived from all NYC vital statistics decennial data merged with weighted PUMS data that contain an approximate 5\% sample of the total population; thus the $95 \%$ confidence intervals attempt to describe the imprecision of our estimates. The ratio between two race/ethnic groups was derived by assigning one group's RMR as the numerator, and the other group's RMR as the denominator. This ratio, $\in$, was used for pairwise comparisons between race/ethnic groups, and between sexes within a race/ethnic group. A rule for evaluating the importance of $\in$ was specified a priori as follows: if the ratio $\in$ comparing race/ethnicity or sex subgroups' mortality ratios was 1.5 or greater (or the reciprocal or lower), representing a $50 \%$ or greater increase in the rate of change in mortality of one of the groups relative to the other, then the ratio $\in$ was considered notably important.

\section{Results}

New York City's population increased $9.8 \%$ from $7,289,839$ in 1990 to $8,004,759$ in 2000 . In this context, the White population declined from approximately 3.2 to 2.8 million (12.5\%). The distributions of Hispanics, African Americans, and Asians residing in NYC in 1990 and 2000, and rates of change reflecting differential immigration patterns are shown in Table 2 to provide the context for understanding differential changes in mortality across racially and ethnically diverse populations. Among Asians, the most notable increases in population size are among Chinese, Indians, and Pakistanis. Increases are observed for Blacks from Africa and the Caribbean, with a notable decrease in native African-American residents. Among Hispanics, notable increases are observed for Mexican, Ecuadorian, and Dominican populations, with the largest number from the Dominican Republic. Notable decreases among Hispanics occurred for both Cuban and Puerto Rican populations. 
Table 2 New York City racial \& ethnic composition and changes, 1990-2000

\begin{tabular}{|c|c|c|c|}
\hline & 1990 & 2000 & $\%$ Change \\
\hline Asian: Total & 509,965 & 829,912 & 62.7 \\
\hline Bangladeshi & 4,955 & 23,709 & 378.5 \\
\hline Cambodian & 2,565 & 2,034 & -20.7 \\
\hline Chinese & 232,908 & 365,782 & 57.1 \\
\hline Filipino & 43,229 & 58,526 & 35.4 \\
\hline Hmong & 6 & 18 & 200.0 \\
\hline Indian & 94,590 & 188,563 & 99.3 \\
\hline Indonesian & 1,443 & 2,640 & 83.0 \\
\hline Japanese & 16,828 & 24,528 & 45.8 \\
\hline Korean & 69,718 & 88,341 & 26.7 \\
\hline Laotian & 366 & 275 & -24.9 \\
\hline Malaysian & 845 & 1,828 & 116.3 \\
\hline Pakastani & 13,501 & 29,205 & 116.3 \\
\hline Sri Lankan & 811 & 2,337 & 188.1 \\
\hline Taiwanese & 6,011 & 4,888 & -18.7 \\
\hline Thai & 3,944 & 4,586 & 16.3 \\
\hline Vietnamese & 8,400 & 12,172 & 44.9 \\
\hline Other Asian & 9,835 & na & na \\
\hline Black: Total & $1,847,049$ & $1,962,164$ & 6.2 \\
\hline African & 53,710 & 122,425 & 127.9 \\
\hline African-American & $1,401,595$ & $1,290,075$ & -7.9 \\
\hline Afro-Caribbean & 391,744 & 549,664 & 40.3 \\
\hline Hispanic: Total & $1,737,927$ & $2,150,965$ & 23.8 \\
\hline Colombian & 84,454 & 104,232 & 23.4 \\
\hline Cuban & 57,019 & 46,225 & -18.9 \\
\hline Dominican & 332,713 & 530,787 & 59.5 \\
\hline Ecuadorian & 78,444 & 139,015 & 77.2 \\
\hline Guatemalan & 15,873 & 21,564 & 35.9 \\
\hline Honduran & 22,167 & 38,336 & 72.9 \\
\hline Mexican & 55,698 & 185,885 & 233.7 \\
\hline Peruvian & 23,257 & 32,397 & 39.3 \\
\hline Puerto Rican & 861,122 & 808,400 & -6.1 \\
\hline Salvadoran & 23,926 & 31,045 & 29.8 \\
\hline Other Hispanics & 183,254 & 213,079 & 16.3 \\
\hline
\end{tabular}

Source: Census 2000: The Latino Population and the Transformation of Metropolitan New York. Latino Data Project: Center for Latin American, Caribbean, and Latino Studies \& Center for Urban Research, The Graduate Center, City University of New York, undated monograph (based on Census 1990 STF4-record A, Census 2000 PUMS Data)

Census Profile: New York City's Asian American Population (Version 2.9) Asian American Federation of New York, December 2004

New York City Department of City Planning, Population Division, NYC2000: Results from the 2000 Census, Socio-Economic Characteristics, 2002

$n a$ indicates not available

Age-adjusted all cause mortality rates for 1990 and 2000 , and relative mortality ratios and $95 \%$ confidence intervals are presented by sex and race/ethnicity in Table 3 .
Table 3 Age and sex-adjusted all cause mortality rates (per 100,000) in New York City for 1990 and 2000 and changes: presented by sex and race/ethnicity

\begin{tabular}{lrrrrr}
\hline & 1990 & \multicolumn{1}{c}{2000} & RMR & $95 \%$ CI & \% Change \\
\hline Men & & & & & \\
White & 1296.5 & 1011.8 & 0.78 & $0.76-0.80$ & -22 \\
Black & 1748.6 & 1252.5 & 0.72 & $0.70-0.73$ & -28 \\
Hispanic & 1068.2 & 859.9 & 0.80 & $0.78-0.83$ & -20 \\
Asian & 456.3 & 611.2 & 1.34 & $1.29-1.39$ & +34 \\
Women & & & & & \\
White & 801.2 & 707.4 & 0.88 & $0.86-0.91$ & -12 \\
Black & 957.8 & 817.2 & 0.85 & $0.83-0.88$ & -15 \\
Hispanic & 566.6 & 535.9 & 0.95 & $0.91-0.98$ & -5 \\
Asian & 296.7 & 396.4 & 1.34 & $1.27-1.40$ & +34 \\
\hline
\end{tabular}

$R M R$, relative mortality ratio of $2000 / 1990$

While all cause mortality rates decreased from 1990 to 2000 for Whites, Blacks and Hispanics, all cause mortality rates increased by $34 \%$ in Asians. Furthermore, in Whites, Blacks, and Hispanics, the percent reduction in all cause mortality was consistently less for women than men, but in Asians, the percent increase in men and women was the same $(34 \%)$. The $95 \%$ confidence intervals for both men and women indicate that the RMR's in Asians were significantly greater than those of other race/ethnic groups $(P<.05)$.

Age and sex-adjusted cause-specific mortality rates (per 100,000) are shown in Table 4. Age-adjusted mortality rates in NYC for 1990 and 2000 decreased with regard to HIV, cancer, stroke, and all cardiovascular diseases. However, mortality caused by diabetes increased by $61 \%$ in men and $52 \%$ in women, significant differences relative to other causes of death $(P<.05)$.

Table 5 provides estimates of relative mortality ratios for selected race/ethnic groups, as well as $\in$, the ratio of these RMR's relative to the White population. For each disease, $\in$ greater than unity represents an increase in health disparity from 1990 to 2000 of a selected racial/ethnic group relative to the White population. An $\in$ less than unity represents lower mortality rates for a racial/ethnic group for a selected disease relative to the White population. Of note, while Asian men had lower stroke-related mortality than White men in 1990, their stroke-related mortality rates exceeded Whites by year 2000, a pattern also experienced by Asian women from diabetes and stroke-related mortalities. Also, while HIV-related mortality improved from 1990 to 2000 in all racial/ethnic groups for both men and women, HIVrelated mortality disparities for Blacks and Hispanics also grew relative to Whites, with the exception of Hispanic women. 
Table 4 Age and sex-adjusted mortality rates (per 100,000) in New York City for 1990 and 2000 presented by disease and sex

\begin{tabular}{lrrlll}
\hline & 1990 & \multicolumn{1}{l}{2000} & RMR & 95\% CI & \% Change \\
\hline Men & & & & & \\
All causes & 1441.0 & 1003.7 & 0.70 & $0.68-0.71$ & -30 \\
HIV & 119.0 & 38.6 & 0.30 & $0.24-0.50$ & -70 \\
Cancer & 293.1 & 232.8 & 0.79 & $0.75-0.84$ & -31 \\
CVD & 1180.2 & 879.5 & 0.75 & $0.72-0.77$ & -25 \\
CHD & 817.1 & 688.3 & 0.84 & $0.81-0.88$ & -16 \\
AMI & 326.7 & 157.7 & 0.48 & $0.44-0.53$ & -52 \\
Stroke & 84.6 & 54.3 & 0.64 & $0.55-0.75$ & -36 \\
Diabetes & 30.5 & 49.1 & 1.61 & $1.32-1.97$ & +61 \\
Women & & & & & \\
All causes & 855.1 & 674.8 & 0.79 & $0.76-0.82$ & -31 \\
HIV & 21.3 & 17.0 & 0.78 & $0.41-1.49$ & -32 \\
Cancer & 190.5 & 163.5 & 0.86 & $0.80-0.92$ & -14 \\
CVD & 820.3 & 616.5 & 0.75 & $0.72-0.79$ & -25 \\
CHD & 569.1 & 467.1 & 0.82 & $0.78-0.87$ & -18 \\
AMI & 209.8 & 104.0 & 0.50 & $0.45-0.55$ & -50 \\
Stroke & 75.2 & 47.4 & 0.63 & $0.54-0.74$ & -37 \\
Diabetes & 26.0 & 39.5 & 1.52 & $1.22-1.89$ & +52 \\
\hline AMI, acute & & & & & \\
\hline
\end{tabular}

$A M I$, acute myocardial infarction; $C H D$, coronary heart disease; $C V D$, cardiovascular disease; $R M R$, relative mortality ratio of 2000/1990

Table 6 lists additional differences for Asian men and women such that mortality ratios for 1990 to 2000 for Asians were at least $50 \%$ greater than corresponding RMR's of other racial/ethnic groups. With regard to all cause and cause-specific mortalities, the greatest differences occurred for diabetes and HIV, for which RMR's among Asians were in general more than twice those of other race/ethnic populations. Another notable finding was that the experience for Asian men was fairly similar to that of Asian women relative to other race/ethnic/sex subgroups.

Another notable difference in RMR's was that the mortality ratio for diabetes in Hispanic men was 55\% greater than that for Hispanic women. With regard to HIV, the RMR for White women was almost four times as great as that for White men $(\in=3.91)$, and more than twice as great among Hispanic women compared with Hispanic men $(\epsilon=2.13)$; Black men had an RMR more than twice that of White men $(\epsilon=2.36)$.

\section{Discussion}

Between 1990 and 2000, significant improvement in mortality occurred in NYC but inequalities persist. Mortality declined at a faster rate than in the previous four decades. However, results identify disparities in trends in all cause mortality, which decreased for Whites, Blacks, and
Table 5 Relative Mortality Ratios by Race/Ethnicity: NYC 1990/ 2000 presented by sex

\begin{tabular}{|c|c|c|c|c|c|c|c|c|c|}
\hline & \multirow{2}{*}{\multicolumn{3}{|c|}{$\frac{\text { Black/White }}{\text { RMR }}$}} & \multirow{2}{*}{\multicolumn{3}{|c|}{$\begin{array}{l}\text { Hispanic/White } \\
\text { RMR }\end{array}$}} & \multirow{2}{*}{\multicolumn{3}{|c|}{$\frac{\text { Asian/White }}{\text { RMR }}$}} \\
\hline & & & & & & & & & \\
\hline & 1990 & 2000 & $\in^{*}$ & 1990 & 2000 & $\in$ & 1990 & 2000 & $\in$ \\
\hline \multicolumn{10}{|l|}{ Men } \\
\hline All causes & 1.35 & 1.24 & .92 & .82 & .85 & 1.04 & .35 & .60 & 1.71 \\
\hline HIV & 1.95 & 4.60 & 2.36 & 1.57 & 2.78 & 1.77 & .04 & .22 & $\mathbf{5 . 5 0}$ \\
\hline Cancer & 1.23 & 1.18 & .96 & .60 & .75 & 1.25 & .41 & .64 & 1.56 \\
\hline CVD & .98 & 1.03 & 1.05 & .59 & .71 & 1.20 & .32 & .56 & 1.75 \\
\hline $\mathrm{CHD}$ & .73 & .88 & 1.21 & .52 & .63 & 1.21 & .29 & .52 & 1.79 \\
\hline AMI & 1.05 & 1.34 & 1.28 & .54 & .67 & 1.24 & .31 & .62 & 2.00 \\
\hline Stroke & 1.89 & 1.69 & .89 & .93 & 1.32 & 1.42 & .69 & 1.24 & 1.80 \\
\hline Diabetes & 2.50 & 2.34 & .94 & 1.08 & 1.80 & 1.67 & .41 & .86 & 2.10 \\
\hline \multicolumn{10}{|l|}{ Women } \\
\hline All causes & 1.20 & 1.16 & .97 & .71 & .76 & 1.07 & .37 & .56 & 1.51 \\
\hline HIV & 5.32 & 6.04 & 1.14 & 3.35 & 3.22 & .96 & .05 & .13 & 2.60 \\
\hline Cancer & .94 & 1.02 & 1.09 & .51 & .60 & 1.18 & .36 & .54 & 1.50 \\
\hline CVD & 1.04 & 1.09 & 1.05 & .62 & .70 & 1.13 & .36 & .57 & 1.58 \\
\hline CHD & .80 & .93 & 1.16 & .55 & .65 & 1.18 & .30 & .50 & 1.67 \\
\hline AMI & .77 & .92 & 1.19 & .62 & .75 & 1.21 & .30 & .61 & 2.03 \\
\hline Stroke & 1.78 & 1.64 & .92 & .99 & 1.15 & 1.16 & .81 & 1.32 & 1.63 \\
\hline Diabetes & 2.73 & 3.17 & 1.16 & 1.59 & 1.99 & 1.25 & .48 & 1.17 & 2.44 \\
\hline
\end{tabular}

$A M I$, acute myocardial infarction; $C H D$, coronary heart disease; $C V D$, cardiovascular disease

$* \in$ reflects the relative change in the selected race/ethnic population's RMR's (numerator) relative to that for the White population (denominator)

The bolded $\in$ values emphasize that the RMR for the minority group was notably greater (at least 1.5 times) than that for whites

Table 6 Notable differences in changes from 1990 to 2000 in all cause and cause specific mortality between Asians and Hispanic and Black populations in NYC by sex

\begin{tabular}{|c|c|c|c|c|c|c|c|c|}
\hline & $\begin{array}{l}\text { All } \\
\text { cause }\end{array}$ & AMI & CHD & CVD & Cancer & DM & HIV & Stroke \\
\hline \multicolumn{9}{|c|}{ Asian Men v. } \\
\hline Black Men & 1.87 & 1.53 & & 1.65 & 1.60 & 2.20 & 2.37 & 2.03 \\
\hline $\begin{array}{l}\text { Hispanic } \\
\text { Men }\end{array}$ & 1.66 & 1.60 & & & & & 3.16 & \\
\hline \multicolumn{9}{|c|}{ Asian Women $v$. } \\
\hline $\begin{array}{l}\text { Black } \\
\text { Women }\end{array}$ & & 1.71 & & 1.50 & & 2.09 & 2.15 & 1.77 \\
\hline $\begin{array}{l}\text { Hispanic } \\
\text { Women }\end{array}$ & & 1.69 & & & & 1.95 & 2.54 & \\
\hline
\end{tabular}

Hispanics, and increased for Asians. Diabetes was found to have a major impact on mortality for Hispanic and Asian men, and Asian women.

Progress has occurred in both poor and wealthy communities suffering from HIV/AIDS through the implementation 
of specific programs and policies expanding testing, assuring linkage to improved and life-saving treatment (e.g., Ryan White HIV CARE Act, AIDS Drug Assistant Program), and promoting medication adherence. The introduction in 1996 of combination antiretroviral therapy with at least one protease inhibitor (HAART) has contributed to the decline in NYC AIDS mortality [25, 26]. The dramatic increase in relative mortality among Asians, Blacks and Hispanics primarily among men with HIV, suggests that focused strategies need to be implemented which address the specific racial/ethnic idiosyncrasies that underlie causes of the epidemic. These trends parallel those cited by Karpati et. al. concerning widening rates of HIV mortality between the wealthiest and poorest neighborhoods in New York City [13]. It is noteworthy that the 2004 Center for Drug Use and HIV Research Report in NYC includes findings for African Americans, Hispanics, and Whites only, with no race category for Asians [27]. This is of importance as recent reports have indicated that the largest increase of HIV/AIDS diagnosis has been among Asian/Pacific Islander men [28].

Obesity continues to increase at an alarming rate [6,29], and is prevalent among all major racial/ethnic groups and all socioeconomic strata [30]. While our data did not allow us to assess specific trends in obesity prevalence, they did demonstrate a dramatic increase in diabetes mortality. Obesity is already having an adverse effect on longevity in certain populations, contributing to the risk of AMI and stroke [31]. Only a moderate weight gain may lead to a striking increase in risk for CHD among South Asians [32, 33], Whites are predisposed to atherogenic dyslipidemia, while type 2 diabetes mellitus (T2DM) is more common in Blacks[34]. Rates of T2DM are increasing rapidly among Asians in their home country, particularly in China and India [35]. In NYC, diabetes has been recognized as a major health problem [36], and was the fourth leading cause of death in the city in 2003[37]. The co-incidence of obesity and diabetes is associated with poorer control of glucose, blood pressure, and cholesterol, thus creating a higher risk for both cardiovascular and microvascular morbidity and mortality $[38,39]$. New and more vigorous strategies are required to curtail increasing mortality, and ultimately reduce mortality differences among racial/ethnic groups. In a report published by the New York City Department of Health and Mental Hygiene entitled Racial/ Ethnic Disparities in Gestational Diabetes Among Pregnant Women in New York City, 1990-2001 [39], the rate of women with gestational diabetes increased $46 \%$ during this time period. Notable disparities were found; the highest prevalence in the city and one of the highest demonstrated increases was observed in South and Central Asian mothers (95\% increase to $11.1 \%$ by 2001), with increases among other Asians of more than 80\% [39]. In Hispanic women, gestational diabetes mellitus increased in Mexican mothers in the past decade ( $4.9 \%$ representing a $96 \%$ increase), and in non-Hispanic Black women and mothers from Caribbean countries or of Caribbean descent $(5.2 \%$ representing a $49 \%$ increase) [39].

Migration has been repeatedly demonstrated to alter a population's pattern of disease and mortality [40]. Following World War II, several pieces of legislation were passed which permitted Chinese, Filipinos, and Asian Indians living in the US to become US citizens. Since 1971, 5 million of the 18 million immigrants to the US were born in Mexico. Asians experienced the greatest increase in reported migration compared with other groups during this period, with 7.3 million most of whom came from the Philippines, followed by China (which includes those from Taiwan to 1990), Viet Nam and India [41]. The Asian population is ethnically heterogeneous, confounded by varying religious affiliations, refugee status, and linguistic diversity, characterized by a bimodal socio-economic distribution since the 1990's.

Our data indicate that Asians have a dramatically higher risk of mortality compared to other racial/ethnic groups. Factors contributing to this finding include the fact that Asian Americans who migrated to the US before 1990 were older during the time period (1990-2000), and thus at higher risk of mortality. The wave of Asians that immigrated to the US prior to 1990 were primarily of a lower socioeconomic status-a determinant of poor health. It is also possible that the relatively larger increase in mortality reflects negative aspects of acculturation during the immigration to New York City since 1990. It is also likely that racial/ethnic mortality differences reflect sociocultural factors such as health and medical care practices [42]. The National Commission on Prevention Priorities, sponsored by the CDC and Robert Wood Johnson and WellPoint Foundations, found that racial and ethnic minorities have lower utilization of the most effective clinical preventive services such as pneumococcal and influenza vaccination, aspirin prophylaxis, and colorectal and cervical cancer screening. Hispanics are $10 \%$ less likely than Whites to receive such services, and African-Americans receive less prevention [43]. In New York City, the Department of Health and Mental Hygiene has reported that rates of timely screening for both breast and cervical cancer are lowest for Asian Americans [44]. In addition, a study commissioned by the Commonwealth Fund found that Asian and Hispanic respondents are less likely than their White counterparts to get medical care when needed, and less likely to receive preventive services. Cultural and linguistic barriers to care are also pervasive among racial and ethnic minorities; for example, the same study reported that Asian Americans are the most likely to report communication problems with their physicians [45]. Finally, genetic differences may also play a factor making Asians 
and other race/ethnic groups in New York City to have a higher incidence of glucose disregulation [46].

Notable differences exist in trends in overall and cause specific mortality among Asian males and females relative to White males and females. Differences in trends between Black and Hispanic males relative to White males were at best sporadic. Karpati et al. noted that inequalities for mortality due to diseases other than AIDS between the poorest and wealthiest communities did not significantly change during this same time period, given the 6.5 fold increase in wealth in the wealthiest relative to the poorest communities [13, 47]. We observed notable differences for all disease categories for both Asian males and females. In New York City, the median household income adjusted for inflation decreased by 2\% from 1990 to 2000 [48], with larger decreases in boroughs other than Manhattan [48]. It is noted however that the 2000 census cites additional poor immigrant families likely to have been present for the 1990 census, but not enumerated [48]. Considering the drop in income may have affected non-White groups more so than Whites, changes in income do not explain disparities between Asians and Hispanic and Black groups. Thus, race/ ethnicity may have an independent contribution to mortality that is masked by looking at differences in income only.

Based on these ecological analyses, disparities in trends in mortality may be due to differential patterns of immigration, income, and obesity, as well as other factors unknown to the authors. In order to combat mortality disparities, it is necessary to focus on behavioral changes that can reverse over-nutrition and inactivity, programs addressing poverty, lack of education, lack of affordable housing, and unemployment-major challenges to immigrants. Eliminating disparities in mortality requires greater attention to social determinants of health including culturally sensitive methods for promoting behavioral change and easier access to health care delivery systems. Interventions focused on behavioral change must be tailored to language, culture, and exposure to the city's economic and environmental stresses. These broader approaches imply public changes in social and economic disparities, a main cause of health inequalities [49].

\section{Limitations}

There are several limitations inherent in this study. First, aggregate groupings for race/ethnicity treat highly heterogeneous populations as homogeneous groups. There are substantial differences in mortality among Hispanic and African-American subgroups according to their birthplace [38, 49], and thus, we expect differences among other racial/ethnic subgroups as well (for example, among Black Americans of Caribbean descent). In an attempt to explain the source of some of this heterogeneity, we have included trends in immigration for the Black, Hispanic, and Asian populations subdivided by country of origin. Mortality data by subgroup were not available, nor were data concerning religious affiliations or rates of Limited English Proficiency -quite diverse in the Asian population [50]. We recognize that behavioral risk factors and access to healthcare services may vary according to country of origin. Data suggest that among Asian Americans, Chinese smoke less than do Koreans, and women much less than men [51]. Dietary habits differ vastly among Asian American subgroups [52]. Finally, rates of preventive screening and health insurance status vary substantially among Asian American subgroups [19]. Tailoring interventions that address cultural diversity may have some unexpected consequences if the design of the intervention presumes one set of assumptions while the targeted group has another [52]. In order to evaluate changes due to interventions tailored to race/ethnicity, summary information needs to be provided and stratified accordingly $[53,54]$. The second limitation is that we do not have data from comparable subjects from the country of origin. Third, data obtained from the Census bureau are likely incomplete and may not account for the substantial undocumented population. Fourth, misclassification could have arisen among individuals with mixed race or incorrect classification on the death certificate, and/or through the introduction of the ICD-10 relative to ICD-9. Fifth, this paper focuses on health disparities at a macro level and as such we do not have data for individuals on confounding factors such as years in the US, age migrated to the US, marital status, size of household, family income, individual countries of origin, and education and health status at time of immigration, smoking history and other comorbidities[55], and notably, genetic predisposition. Sixth, trends in family income during this period were available only for New York State and not New York City. Most importantly, data on income, healthcare access, and trends in obesity prevalence to better understand changes in social disparities, are not available for the Asian population. Furthermore, because changes in mortality from 1990 to 2000 may reflect both immigration patterns prior to 1990 and those during the time interval, we cannot explain the relative contribution of each to observed mortality rates. The strength of the study however, is that these census-derived data are population-based, with similar data collection methodologies used across all racial/ethnic groups. These trends form an important framework for evaluating further trends when 2010 data become available in coming years.

\section{Conclusion}

Reductions in HIV, cancer, CVD, CHD, AMI, and strokerelated mortality were found citywide for both men and 
women. However, disparities exist with regard to trends in HIV-related mortality, with Black, Hispanic, and Asian men having notably higher rates when compared to White men. Diabetes mortality rates rose dramatically citywide affecting mainly Hispanic and Asian men. Additionally, the increase in diabetes-related mortality among Asian women was more than twice that of White women. Changes in mortality among Asians were dramatic and exceeded those of other minority groups. Public health officials need to consider immigration patterns along with race/ethnicity and sex in designing, implementing, and evaluating interventions to prevent disease-related mortality, with a goal to eliminate disparities. These data serve as an important reference for future research.

Acknowledgments The research was supported by NIH grant 5 P60 MD000514-06, National Center on Minority Health \& Health Disparities Comprehensive Center of Excellence in Health Disparities Research, Bronx Center to Reduce and Eliminate Ethnic and Racial Health Disparities. Dr. Islam's contribution was made possible by NIH grants P60 MD000538 and R24MD001786, National Center on Minority Health \& Health Disparities, and CDC grant 1U48DP001904. The authors thank Jing Fang, MD, Epidemiologist, Division of Heart Disease and Stroke Prevention, National Center for Chronic Disease Prevention and Health Promotion, Centers for Disease Control and Prevention, Atlanta, Georgia, for analyzing the $\mathrm{NYCDOH}$ computer tapes and sharing the aggregate data with us for our analysis. The manuscript contents are solely the responsibility of the authors and do not necessarily represent the official views of the NCMHD/CDC.

Open Access This article is distributed under the terms of the Creative Commons Attribution Noncommercial License which permits any noncommercial use, distribution, and reproduction in any medium, provided the original author(s) and source are credited.

\section{References}

1. Differences in Infant Mortality Between Blacks, Whites-United States, 1980-1991. Centers for disease control and prevention (CDC). MMWR Morb Mortal Wkly Rep. 1994;43(16):288-9.

2. Liao Y, Cooper RS. Continued adverse trends in coronary heart disease mortality among Blacks, 1980-1991. Public Health Rep. 1995;110:572-9.

3. Second National Reports on Quality and Disparities Find Improvements in Health Care Quality, Although Disparities Remain. Agency for Healthcare Research and Quality. 2004 National Healthcare Quality Report and 2004 National Healthcare Disparities Report.

4. Meara ER, Richards S, Cutler DM. The gap gets bigger: changes in mortality and life expectancy, by education, 1981-2000. Health Aff. 2008;27(2):350-60.

5. Center for Disease Control and Prevention. Screening for chronic Hepatitis B among Asian/Pacific Islander populations-NYC, 2005. MMWR Morb Mortal Wkly Rep. 2006;55:505-9.

6. Flegal KM, Carroll MD, Ogden CL, Johnson CL. Prevalence and trends in obesity among US adults, 1999-2000. JAMA. 2002; 288:1723-7.

7. Ogden CL, Flegal KM, Carroll MD, Johnson CL. Prevalence and trends in overweight among US children and adolescents, 19992000. JAMA. 2002;288:1728-32.
8. Mokdad AH, Ford ES, Bowman BA, et al. Diabetes trends in the US: 1990-1998. Diabetes Care. 2000;22:1278-83.

9. New York City Department of Planning. Table PL-3A: Total Population by Mutually Exclusive Races and Hispanic Origin, New York City and Boroughs, 1990 and 2000.

10. Najam A. Portrait of a giving community: Philanthropy by the Pakistani-American Diaspora. Cambridge: Global Equity Initiative Asia Center, Harvard University Press; 2006.

11. New York City Department of City Planning, Population Division, NYC2000: Results from the 2000 Census, Socio-Economic Characteristics, 2002.

12. The Health of Immigrants in New York City A Report of the New York City Department of Health and Mental Hygiene, June 2006.

13. Adam M, Karpati AM. Bassett MT Neighborhood mortality inequalities in New York City, 1989-1991 and 1999-2001. J Epidemiol Community Health. 2006;60:1060-4.

14. Evans RG, Stoddart GL. Producing health, consuming health care. In: Evans RG, Barer ML, Marmor TR, editors. Why are some people healthy and others not? The determinants of health of populations. New York: Aldine DeGruyter; 1994. p. 29-64.

15. Rana JS, Mukamal KJ, Morgan JP, Muller JE, Mittleman MA. Obesity and the risk of death after acute myocardial infarction. Am Heart J. 2004;147(5):841-6.

16. Changing the US Health Care System. Ronald Andersen, Thomas H. Rice, Abdelmonem A. Afifi, Gerald F., Wiley, 2007.

17. Clarke P, O'Malley PM, Johnston LD, Schulenberg JE. Social disparities in BMI trajectories across adulthood by gender, race/ ethnicity and lifetime socio-economic position: 1986-2004. Int J Epidem Int J Epidemiol. 2009;38(2):499-509.

18. Steering Committee of the Western Pacific Region of the World Health Organization, the International Association for the Study of Obesity, and the International Obesity Task Force: The AsiaPacific Perspective: Redefining Obesity and its Treatment. Melbourne, Australia, Health Communications Australia, 2000.

19. Barnes PM, Adams PF, Powell-Griner E. Health characteristics of the Asian adult population: United States, 2004-2006. Hyattsville, MD: National Center for Health Statistics; 2008.

20. Department of Health and Human Services. Healthy People 2010: understanding and improving health. 2nd ed. Washington, D.C: Government Printing Office; 2000.

21. World Health Organization: Manual of the International Statistical Classification of Diseases, Injuries, and Causes of Death, Based on the Recommendations of the Ninth Revision Conference, 1975. Geneva, World Health Org. 1977.

22. World Health Organization. International statistical classification of diseases and health related problems (The) ICD-10. 2nd ed. Geneva: World Health Org.; 2004.

23. National Vital Statistics Report, 6/28/2006 http://www.cdc.gov/ mchs/fastats/lcod.htm.

24. Human Immunodeficiency Virus Infection Codes and Official Guidelines for Coding and Reporting ICD-9-CM MMWR Morb Mortal Wkly Rep 43(RR-12); 11-19.

25. Wong T, Chiasson MA, Reggy A, Simonds RJ, Heffess J, Loo V. Antiretroviral therapy and declining AIDS mortality in New York City. J Urban Health. 2000;77(3):492-500.

26. Fordyce EJ, Singh TP, Nash D, Gallagher B, Forlenza S. Survival rates in NYC in the era of combination ART. J Acquir Immune Defic Syndr. 2002;30:111-8.

27. Center for Drug Use and HIV Research Spring/Summer newsletter 2004 vol 7 issue 1.

28. Centers for Disease Control, Prevention. Trends in HIV/AIDS diagnoses among men who have sex with men-33 states, 20012006. MMWR Morb Mortal Wkly Rep. 2008;57(25):681-6.

29. Centers for Disease Control and Prevention: Prevalence of diabetes and impaired fasting glucose in adults: United States, 19992000. MMWR Morb Mortal Wkly Rep 2003; 52:833-837. 
30. Mokdad AH, Bowman BA, Ford ES, Vinicor F, Marks JS, Koplan JP. The continuing epidemics of obesity and diabetes in the United States. JAMA. 2001;286:1195-200.

31. Olshansky SJ, Passaro DJ, Hershaw RC, et al. A potential decline in life expectancy in the United States in the 21st century. N Engl J Med. 2005;352:1138-45.

32. McKeigue PM, Ferrie JE, Pierpoint T, Marmot MG. Association of early-onset coronary heart disease in South Asian men with glucose intolerance and hyperinsulinemia. Circulation. 1993; 87:152-61.

33. Miller GJ, Beckles GL, Maude GH, Carson DC, Alexis SD, Price SG, Byam NT. Ethnicity and other characteristics predictive of coronary heart disease in a developing community: principal results of the St James Survey, Trinidad. Int J Epidemiol. 1989; 18:808-17.

34. Bedi US, Singh S, Syed A, Aryafar H, Arora R. Coronary artery disease in South Asians: an emerging risk group. Cardiol Rev. 2006;14(2):74-80.

35. Joslin Diabetes Center. Asian American Diabetes Initiative. http://aadi.joslin.harvard.edu/.

36. Kim M, Burger D, Matte T. Diabetes in New York City: Public Health Burden and Disparities. New York: New York City Department of Health and Mental Hygiene; 2006.

37. Santora M: City officials aim to track how diabetics manage illness. New York Times, 8 July 2005.

38. Fang J, Alderman MH. Impact of the increasing burden of diabetes on acute myocardial infarction in New York City: 19902000. Diabetes. 2006;55(3):768-73.

39. Thorpe LE, Berger D, Ellis JA, Bettegowda VR, Brown G, Matte T, Bassett M, Frieden TR. Trends and racial/ethnic disparities in gestational diabetes among pregnant women in New York City, 1990-2001. Am J Public Health. 2005;95(9):1536-9.

40. Gerber LM, Madhavan S. Epidemiology of coronary heart disease in migrant Chinese population. Med Anthropol. 1980;4:307-20.

41. Le, C.N. "The 1965 Immigration Act." Asian-Nation: The Landscape of Asian America: http://www.Asian-nation.org/1965immigration-act.shtml.

42. National Commission for Prevention Priorities. Preventive Care: A National Profile on Use, Disparities, and Health Benefits. Washington, DC: Partnership for Prevention. August 2007.

43. Karpati A, Galea S, Awerbuch T, Levins R. Variability and vulnerability at the ecological level: implications for understanding the social determinants of health. Am J Public Health. 2002;92(11):1768-72.
44. Thorpe LE, Mostashari F, Feldman G, Karpati AM, Cobb LK, Helgerson SD, Frieden TR. Cancer screening in New York City: we can do much better. NYC Vital Signs. 2003;2(2):1-4.

45. A. C. Beal, M. M. Doty, S. E. Hernandez, K. K. Shea, and K. Davis, Closing the Divide: How Medical Homes Promote Equity in Health Care: Results from the Commonwealth Fund 2006 Health Care Quality Survey, The Commonwealth Fund, June 2007.

46. Thorpe LE, Upadhyay UD, Chamany S, Garg R, Mandel-Ricci J, Kellerman S, Berger DK, Frieden TR, Gwynn C. Prevalence and control of diabetes and impaired fasting glucose in New York City. Diabetes Care. 2009;32(1):57-62.

47. Pulling Apart in New York: An Analysis of Income Trends in New York State. www.fiscalpolicy.org/PullingApartInNewYork April2008.pdf.

48. New York City 2000. Results from the 2000 Census. Socioeconomic Characteristics. New York City Department of City Planning, Population Division. www.nyc.gov/html/dcp/pdf/census/ sociopp.pdf.

49. Fang J, Madhavan S, Alderman MH. The influence of birthplace on mortality among Hispanic residents of New York City. Ethn Dis. 1997;7(1):55-64.

50. Richardson E. Allen. East Comes West: Asian Religions and Cultures in North America. New York: Pilgrim Press; 1985.

51. Ma GX, Shive SE, Tan Y, Feeley RM. The impact of acculturation on smoking in Asian American homes. JHCPU. 2004;15: 267-80.

52. Frohlich KL, Potvin L. Transcending the known in public health practice: the inequality paradox: the population approach and vulnerable populations. Am J Public Health. 2008;98(2):216-21.

53. Islam N, Trinh-Shevrin C, Rey M. (forthcoming 2009) Introduction: Towards a Contextual Understanding of Asian American Health. Asian American Communities and Health: Context, Research, Policy, and Action. Jossey Bass Publishers: San Francisco.

54. Trinh-Shevrin C, Islam N, Tandon D, Abesamis N, As-Joe HH, Rey M (2007) Using Community-based Participatory Research as a Guiding Framework for Health Disparities Research Centers. Progress in Community Health Partnerships: Research, Education, and Action, Volume 1, Issue 2.

55. Koster A, Leitzmann MF, Schatzkin A, Adams KF, van Eijk JT, Hollenbeck AR, Harris TB. The combined relations of adiposity and smoking on mortality. Am J Clin Nutr. 2008;88:1206-12. 